\title{
Dominant height growth equations including site attributes in the generalized algebraic difference approach
}

\author{
Andrés Bravo-Oviedo, Margarida Tomé, Felipe Bravo, Gregorio Montero, and \\ Miren del Río
}

\begin{abstract}
We present a new dynamic dominant height growth model based on Cieszewski's generalized algebraic difference approach (GADA) advanced dynamic site equation strengthened by the use of explicit climate and soil variables (i.e., $H=f\left(H_{0}, T_{0}, T\right.$, site conditions)). The results suggest that the inclusion of climatic variables would improve the applicability of the inter-regional model in regions in which climate and soil type lead to intra-regional variability. The new model reduces the bias present in a previous dynamic model that did not include climatic attributes and improves the model efficiency across the different age classes. Climate has a multiplicative effect on dominant tree growth in the early development stages $(<20$ years) and an additive effect in older stands.
\end{abstract}

Résumé : Nous présentons ici un nouveau modèle dynamique de croissance en hauteur dominante fondé sur l'équation de la méthode de la différence algébrique généralisée (GADA) de l'indice de qualité de station de Cieszewski renforcée par l'utilisation des variables explicites du climat et du sol, c.-à-d. $H=f\left(H_{0}, T_{0}, T\right.$, état du site). Les résultats indiquent que l'inclusion des variables climatiques permettrait d'améliorer l'applicabilité du modèle interrégional dans les régions où le climat et le type de sol sont à l'origine de la variabilité intrarégionale. Le nouveau modèle permet de réduire le biais présent dans un modèle dynamique précédent qui n'incluait pas les caractéristiques climatiques et améliore l'efficacité de ce modèle pour l'ensemble des classes d'âge. Le climat exerce un effet multiplicateur sur la croissance des arbres dominants durant les premiers stades de développement ( $<20$ ans) et un effet additif dans les vieux peuplements.

[Traduit par la Rédaction]

\section{Introduction}

Mediterranean maritime pine (MMP; Pinus pinaster Ait.) is widely distributed in the Mediterranean basin, occupying approximately $4 \times 10^{6}$ ha (Ribeiro et al. 2001). The species grows in a wide range of climatic conditions; from pure Mediterranean climate conditions such as those found in eastern Spain, Italy, and southern France to the continental climate of inland Spain or the Atlantic climate of western France, Portugal, and northwestern Spain. Soil origin varies, from igneous and metamorphic rocks such as granite or gneiss in Portugal and western Spain to eocene sands in central Spain, bunt sandstone in eastern Spain, or dolomite in southeastern Spain and eastern Italy. Climatic and edaphic variability combined with the isolated nature of the stands leads to genetic variation (Salvador et al. 2000; GonzálezMartínez et al. 2001), which is reflected in tree attributes such as straightness (Río et al. 2004), drought tolerance, or growth (Alía et al. 1997).

In recent years, various models have attempted to explain the regional variability in growth (Calama et al. 2003; Wang et al. 2004; Álvarez-González et al. 2005; Adame et al. 2006). However, intra-regional variability can be significant in limited areas, such as those with Mediterranean conditions, in which different growth patterns and growth values for certain attributes are found within the same natural region. In addition, forest researchers are facing new challenges beyond the scope of regional studies, as climate change and its effect on species distribution as well as on tree and stand growth becomes more evident.

The Mediterranean area is considered to be more sensitive to climate change than other areas (IPCC 1996). The mechanisms by which plants adapt to their changing environment are not expected to develop as quickly as would be required to keep pace with the changing climate, so adaptive forest management strategies are needed to obtain goods and services from the forest in a sustainable manner. Including local growth trends could help to develop these strategies.

Mixed effects modeling is a commonly used approach for

Received 15 October 2007. Accepted 6 June 2008. Published on the NRC Research Press Web site at cjfr.nrc.ca on 30 July 2008.

A. Bravo-Oviedo, ${ }^{\mathbf{1}}$ G. Montero, and M. del Río. Departamento Sistemas y Recursos Forestales — Deparment of Forest Systems and Resources, Centro de Investigación Forestal, Instituto Nacional de Investigación y Tecnología Agraria y Alimentaria and Institute on Sustainable Forest Management. Ctra. A. Coruña, km 7,5 28040, Madrid, Spain.

M. Tomé. Technical University of Lisbon, Instituto Superior de Agronomia. Centro de estudos Florestais, Tapada de Ajuda, 1349-017, Lisboa, Portugal.

F. Bravo. Sustainable Forest Management Group, University of Valladolid and Institute on Sustainable Forest Management, Avda, Madrid, 44, 34004 Palencia, Spain.

${ }^{1}$ Corresponding author (e-mail: bravo@inia.es). 
modelling local variability (Lappi and Bailey 1988; Fang et al. 2001; Calama and Montero 2004). All the same, other approaches that take into account individual trends, such as the varying parameter method proposed by Cieszewski et al. (2000) for site index modelling, may also be appropriate.

If the growth pattern and site productivity are expected to change, then variables related to site productivity such as dominant height and site index estimation would also change, since forest site is considered to be the integrator of many environmental factors that affect tree growth and distribution (Barnes et al. 1997). Accurate forest site quality estimation should consider as many of these factors as possible. However, planning budgets, ecological processes, uncertainty, and model building complexity favour simple models that, in many cases, are accurate enough for large scale management.

Owing to the importance of site quality in forest dynamics, site dependent height-age modelling continues to be one of the most important elements in forest research (Oliver and Larson 1996). The work of Bailey and Clutter (1974) marked an important step forward in site index modelling by incorporating the analytical procedure to achieve base age invariance in the algebraic difference approach (ADA). The concurrence of both polymorphism and variable asymptote along with base age invariance in the work of Cieszewski and Bailey (2000) is recognized as another milestone in site index modelling. In this generalization of the ADA (hereinafter referred to as GADA), a parameter or a set of parameters related to site is identified and the relationship with an unobservable variable, $X$, or the growth intensity factor (GIF) is determined. The equation for that variable is then solved and substituted with the initial conditions. The final model is a three-dimensional dynamic equation of type $Y=f\left(Y_{0}, t_{0}, t\right)$, where subindex zero indicates initial conditions for estimation of $Y$ variable at time $t$.

Attempts to prove the viability of using dynamic growth models to evaluate cause-effect relationships exist. For example, Woollons et al. (1997) used an ADA approach including climatic variables, although they found no significant improvement for dominant height growth. With regard to the use of the GADA formulation, Cieszewski and Bailey (2000) related the GIF to climate, water availability, and other site descriptors.

The flexibility of the GADA formulation permits the inclusion of the relationship between parameters and site productivity proxies, such as ecological regions. Bravo-Oviedo et al. (2007) fitted a region-based site index model for MMP in southwestern Europe using GADA formulation. Regions were defined according to seed provenances, geographic continuity, and previous ecological classification. They selected the three parameter model developed by Cieszewski (2001). Two parameters were found to be site specific and the third one to be common to all sites, which, when expanded on a regional basis, led to the improvement of estimates. However, the observable heterogeneity within each region indicated that more flexibility is required to reflect the great variability in dominant height growth for the species. The variability of the species is thought to be caused by its sensitivity to environmental factors, perhaps in this case as a result of the limiting conditions of the Mediterranean region.
The purpose of this work is to develop an empirical sitedependent height model capable of explaining, as far as possible, the regional growth pattern of MMP by developing a dynamic growth model using the third method proposed by Cieszewski (2001) and then testing different growth theory assumptions by incorporating climatic and soil attributes. We assess the consistency of the results throughout the natural regions by analyzing whether the model reflects the local growth trend related to climate and soil parental material compared with a previous regional model.

\section{Materials and methods}

\section{Study area and database}

The study area is located in inland Spain. Four geographic regions are covered in the study: northern plateau stands (NPS), the Iberian mountain range stands (IMS), the central mountain range stands (CMS), and the south east stands (SES). Figure 1 shows a digital terrain model with the stand locations.

The data came from the stem analysis in a permanent experimental sample plot network and its measurements were provided by Centro de Investigación Forestal - Instituto Nacional de Investigación y Tecnología Agraria y Alimentaria (CIFOR-INIA; Montero et al. 2004). Table 1 shows the main characteristics of the database. For more information on this database see Bravo-Oviedo et al. (2007).

Topographic and climatic variability are characteristic features of the Mediterranean basin, which may help to explain the different growth patterns in forest species. Therefore, a physiographic and climatic characterization of every plot was performed to investigate the likely effect of climate on the growth pattern. A standard 30 year period (19611990) was used for climatic data collection at each location. This was possible thanks to the GENPT and COMPLET programs (Manrique and Fernández-Cancio 2005) using the nearest permanent meteorological stations to generate the climatic data at each location according to UTM coordinates and elevation. The meteorological stations belong to the $\mathrm{Na}-$ tional Institute of Meteorology. Topographic attributes were extracted from a digital terrain model with the help of ArcGIS Version 9 of ESRI Inc. (2006). Table 2 shows the mean, maximum, minimum, and standard deviation values for 27 climatic variables recorded and used in this study.

Soil data were obtained in a subsample according to elevation and soil parental material. In 65 plots we dug a pit where samples of every soil horizon were extracted for analysis in the laboratory. The soil attributes measured were water $\mathrm{pH}$, conductivity, organic matter (oxidizable organic carbon using the Walkley-Black Method), carbonates, and active calcium (using Bernard's calcimeter), phosphorus (according to Olsen's Method), exchangeable calcium, magnesium, potasium, and sodium (according to the Ammonium acetate method), cation exchange capacity (determined according to Bascomb's procedure), nitrogen (according to Kjeldahl's method), and total organic matter. Table 3 presents a brief description of soil attributes.

\section{Analysis}

Data analysis was performed in three steps: (i) factor analysis for data reduction and identification of significant 
Fig. 1. Study area and stand locations. NPS, northern plateau stands; CMS, central mountain range stands; IMS, Iberian mountain range stands; SES, south east stands.

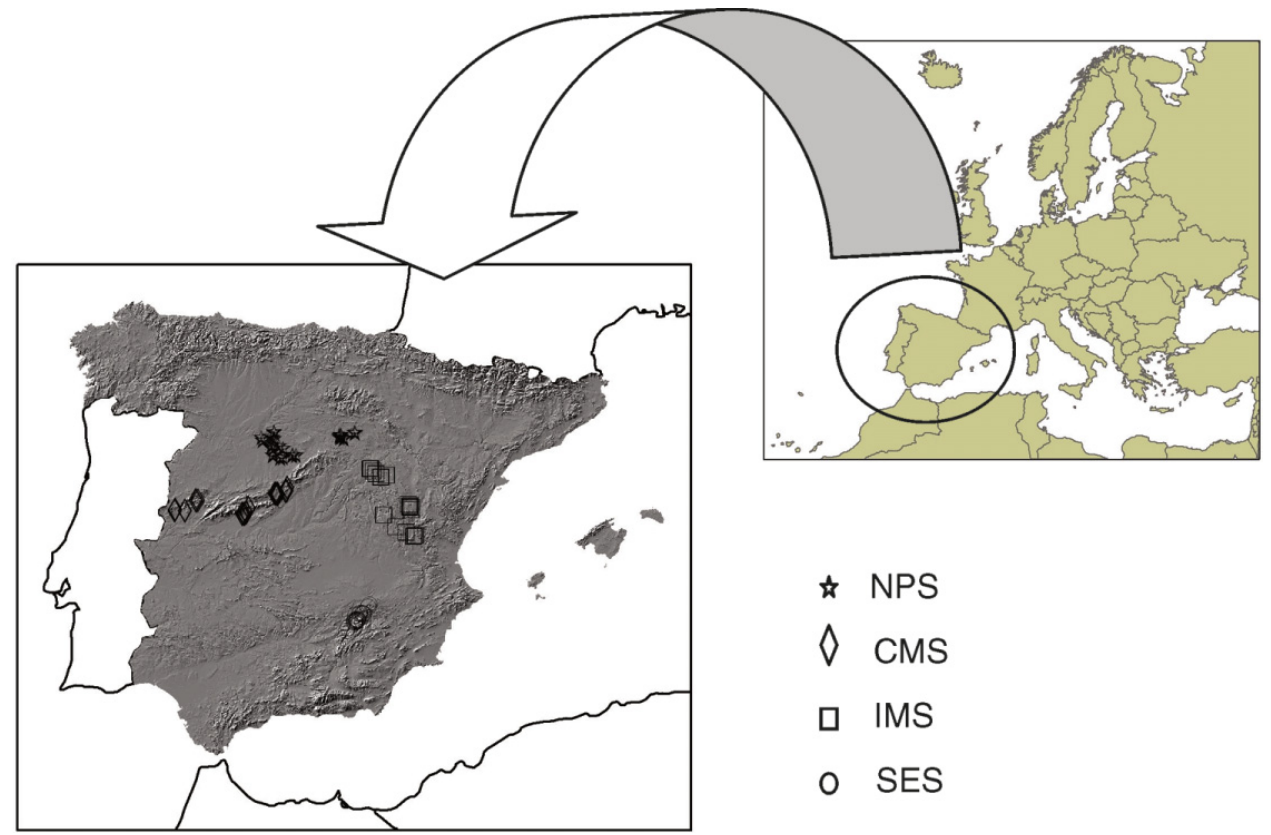

Table 1. Summary of the data used in the study by region and combined.

\begin{tabular}{|c|c|c|c|c|c|c|c|}
\hline \multirow[b]{2}{*}{ Region } & \multirow[b]{2}{*}{$\begin{array}{l}\text { No. of } \\
\text { stands }\end{array}$} & \multicolumn{3}{|l|}{ Age } & \multicolumn{3}{|c|}{ Dominant height } \\
\hline & & Mean & Min. & Max. & Mean & Min. & Max. \\
\hline NPS & 30 & $64(19.89)$ & 33 & 106 & $15.02(2.77)$ & 9.21 & 20.49 \\
\hline CMS & 39 & $68(26.67)$ & 25 & 140 & 17.77 (4.39) & 8.3 & 28.25 \\
\hline IMS & 31 & $93(33.25)$ & 41 & 170 & $13.93(3.26)$ & 7.6 & 20.07 \\
\hline SES & 23 & $100(31.62)$ & 61 & 180 & 17.01 (2.99) & 9.02 & 21.67 \\
\hline Total & 123 & $80(32.91)$ & 25 & 180 & $15.80(3.90)$ & 7.6 & 28.25 \\
\hline
\end{tabular}

Note: Values in parentheses are SDs. NPS, northern plateau stands; CMS, central mountain range stands; IMS, Iberian mountain range stands; SES, south east stands.

climate and soil covariates that would account for regional differences, (ii) growth model building and fitting according to several growth assumptions, and (iii) growth model evaluation in terms of applicability and performance at each location.

\section{Factor analysis}

Factor analysis was performed to assess the regional differences according to climatic and edaphic attributes separately, since soil data were not available for the whole data set. The multivariate technique was used in an exploratory way to reduce the dimensionality of the data matrix (Dillon and Goldstein 1984). Variables were standardized and factors were extracted with the principal components so that by rotating them through the Varimax procedure (SAS Institute Inc. 2004b) each factor accounted for the maximum variance. The selection of variables was performed according to Kaiser's measure of sample adequacy (MSA; Dillon and Goldstein 1984). Variables were retained if the individual MSA was acceptable $(\geq 0.5)$. The analysis was considered appropriate if the global MSA was $>0.8$ (Hair et al. 1999).

\section{Model building and fitting}

Cieszewski (2001) defined three methods of deriving advanced dynamic site index equations and proposed the following advanced dynamic equation that we use in this study (eq. 1). The same parameter notation as that of eqs. 16, 17, and 18 in Cieszewski's (2001) work was used.

[1] $Y=Y_{0}\left(\frac{t}{t_{0}}\right)^{v+\delta}\left(t_{0}^{\delta} R+\kappa\right)\left(t^{\delta} R+\kappa\right)^{-1}$

where $R=Z_{0}+\sqrt{Z_{0}^{2}+\frac{2 \kappa Y_{0}}{t_{0}^{v+\delta}}}$ for $Z_{0}=\frac{Y_{0}}{t_{0}^{v}}-\eta$, which is the most likely positive solution, $\kappa=2 \alpha \gamma^{\prime}$ and $\gamma^{\prime}=e^{\gamma}$. $Y$ is any actual growth attribute, $t$ is actual age, $Y_{0}$ and $t_{0}$ are initial conditions, and Greek letters are parameters to be estimated. $\gamma^{\prime}, \alpha$, and $\eta$ affect site productivity and $\delta$ is an exponential time transformation.

The solution proposed by Cieszewski (2001) (simplified to $v=0$ ) leads to a general case resulting in a polymorphic model with variable asymptotes if $\gamma^{\prime} \neq 0 \neq \alpha$, the latter being the final dynamic model used in this study.

The growth model was fitted following the varying pa- 
Table 2. Physiographic attributes and climate conditions during the standard period (1961-1990).

\begin{tabular}{|c|c|c|c|c|c|}
\hline Attribute & Units & Min. & Mean & Max. & SD \\
\hline Elevation & $\mathrm{m}$ & 377 & 975 & 1437.0 & 248.7 \\
\hline Latitude & $\circ$ & 38.0 & 40.3 & 42.0 & 1.1 \\
\hline Slope & $\%$ & 0.0 & 18.8 & 63.7 & 13.7 \\
\hline Aspect & $\circ$ & - & 174 & 348.7 & 106.6 \\
\hline Insolation & $\mathrm{W} / \mathrm{m}^{2}$ & 0.35 & 0.96 & 1.37 & 0.17 \\
\hline Annual rainfall & $\mathrm{mm}$ & 410.5 & 577.6 & 790.8 & 94.2 \\
\hline Winter rainfall & $\mathrm{mm}$ & 107.6 & 181.4 & 307.1 & 54.1 \\
\hline Spring rainfall & $\mathrm{mm}$ & 118.4 & 165.8 & 220.3 & 25.7 \\
\hline Summer rainfall & $\mathrm{mm}$ & 46.4 & 74.2 & 121.1 & 18.6 \\
\hline Autumn rainfall & $\mathrm{mm}$ & 106.7 & 156.1 & 233.1 & 27.8 \\
\hline Mean annual temperature & ${ }^{\circ} \mathrm{C}$ & 9.0 & 12.1 & 16.0 & 1.7 \\
\hline Mean lowest temperature & ${ }^{\circ} \mathrm{C}$ & 0.3 & 3.2 & 7.0 & 1.6 \\
\hline Mean highest temperature & ${ }^{\circ} \mathrm{C}$ & 19.6 & 22.6 & 26.7 & 1.7 \\
\hline Min. temperature of coldest month & ${ }^{\circ} \mathrm{C}$ & -4.6 & -1.4 & 2.2 & 1.8 \\
\hline Absolute min. temperature & ${ }^{\circ} \mathrm{C}$ & -14.7 & -8.3 & -3.5 & 2.6 \\
\hline Thermal oscilation & ${ }^{\circ} \mathrm{C}$ & 10.3 & 12.5 & 14.5 & 0.7 \\
\hline Max. temperature of warmest month & ${ }^{\circ} \mathrm{C}$ & 27.8 & 31.0 & 35.4 & 1.7 \\
\hline Absolute max. temperature & ${ }^{\circ} \mathrm{C}$ & 33.4 & 37.0 & 41.3 & 1.8 \\
\hline Evapotranspiration (ET) & $\mathrm{mm}$ & 597.9 & 701.6 & 850.4 & 58.0 \\
\hline Winter ET & $\mathrm{mm}$ & 20.2 & 34.5 & 46.8 & 6.9 \\
\hline Spring ET & $\mathrm{mm}$ & 112.2 & 137.8 & 164.5 & 11.4 \\
\hline Summer ET & $\mathrm{mm}$ & 323.1 & 367.5 & 444.5 & 28.4 \\
\hline Autumn ET & $\mathrm{mm}$ & 139.2 & 161.8 & 194.6 & 13.4 \\
\hline Months with frost & months & 0.0 & 2.8 & 5.0 & 1.5 \\
\hline Vegetative period length & months & 5.0 & 6.2 & 9.0 & 1.1 \\
\hline Drought length & months & 2.2 & 3.8 & 4.8 & 0.7 \\
\hline
\end{tabular}

Table 3. Descriptive statistics of soil attributes.

\begin{tabular}{llllll}
\hline Attribute & Units & Min. & Mean & Max. & SD \\
\hline Fine fraction & $\%$ & 16.9 & 60.3 & 100.0 & 26.7 \\
Coarse fraction & $\%$ & 0.0 & 39.7 & 83.1 & 26.7 \\
Sand & $\%$ & 20.5 & 65.0 & 93.3 & 21.2 \\
Clay & $\%$ & 2.0 & 11.5 & 49.7 & 10.8 \\
Silt & $\%$ & 1.6 & 23.5 & 61.9 & 14.2 \\
CCC & - & 0.0 & 0.2 & 2.5 & 0.4 \\
CIL & - & 0.0 & 0.1 & 0.5 & 0.1 \\
Permeability & - & 1.0 & 4.0 & 5.0 & 1.3 \\
pH & - & 5.1 & 6.6 & 8.7 & 0.9 \\
Water holding capacity & $\mathrm{mm}$ & 12.8 & 104.3 & 367.8 & 74.7 \\
Equivalent humidity & $\mathrm{mm}$ & 7.0 & 16.7 & 35.4 & 7.6 \\
Organic matter & $\%$ oxidable & 0.1 & 1.3 & 8.5 & 1.3 \\
Calcium & $\mathrm{ppm}$ & 100.1 & 1071.7 & 5496.0 & 1231.3 \\
Sodium & $\mathrm{ppm}$ & 2.4 & 22.5 & 64.2 & 16.3 \\
Potasium & $\mathrm{ppm}$ & 15.9 & 84.7 & 498.9 & 99.1 \\
Phosphorous & $\mathrm{ppm}$ & 0.0 & 0.8 & 14.6 & 2.7 \\
Magnesium & $\mathrm{ppm}$ & 14.1 & 253.3 & 3201.4 & 561.7 \\
Nitrogen & $\%$ & 0.0 & 0.1 & 0.3 & 0.0 \\
Carbontes & $\%$ & 0.0 & 4.1 & 38.5 & 8.8 \\
Active carbonates & $\%$ & 0.0 & 0.4 & 6.3 & 1.1 \\
Conductivity & $\mathrm{mmho} \cdot \mathrm{cm}^{-1}$ & 0.0 & 0.1 & 0.4 & 0.1 \\
Cation exchange capacity & $\mathrm{mequiv} \cdot 100 \mathrm{~g}^{-1}$ & 3.9 & 10.8 & 32.0 & 5.8 \\
Bases sum & $\mathrm{mequiv} \cdot 100 \mathrm{~g}^{-1}$ & 1.0 & 7.8 & 43.6 & 9.8 \\
Saturation rate & $\%$ & 6.9 & 57.6 & 186.3 & 38.8 \\
\hline Not CCC, compact & & & & & \\
\hline
\end{tabular}

Note: CCC, compactness capacity coefficient according to Nicolás and Gandullo (1966); CIL, silt impermeability coefficient according to Nicolás and Gandullo (1966). 
Table 4. Factor analysis results.

\begin{tabular}{|c|c|c|}
\hline Variable & Factor 1 & Factor 2 \\
\hline \multicolumn{3}{|l|}{ Climatic and physiographic data } \\
\hline Elevation & -0.87 & 0.04 \\
\hline Latitude & -0.24 & -0.36 \\
\hline Slope & 0.15 & 0.54 \\
\hline Aspect & -0.05 & 0.24 \\
\hline Insolation & -0.11 & 0.1 \\
\hline Annual rainfall & 0.23 & 0.95 \\
\hline Winter rainfall & 0.55 & 0.78 \\
\hline Summer rainfall & -0.84 & -0.06 \\
\hline Autumm rainfall & 0.35 & 0.85 \\
\hline Mean anual temperature & 0.93 & 0.25 \\
\hline Mean lowest temperature & 0.89 & 0.31 \\
\hline Mean highest temperature & 0.86 & 0.31 \\
\hline Min. temperature of the coldest month & 0.84 & 0.31 \\
\hline Absolute min. temperature & 0.82 & 0.43 \\
\hline Max. temperature of the warmest month & 0.9 & 0.19 \\
\hline Absolute max. temperature & 0.67 & -0.02 \\
\hline Winter ET & 0.87 & 0.31 \\
\hline Spring ET & 0.95 & 0.07 \\
\hline Summer ET & 0.86 & 0.29 \\
\hline Autumn ET & 0.86 & 0.29 \\
\hline Months with frost & 0.09 & 0.03 \\
\hline Drought length & 0.93 & 0.08 \\
\hline Eigenvalue & 11.98 & 3.65 \\
\hline Variance explained & 0.58 & 0.18 \\
\hline Cumulative variance explained & 0.58 & 0.76 \\
\hline \multicolumn{3}{|l|}{ Edaphic data } \\
\hline Fine fraction & -0.02 & -0.26 \\
\hline Coarse fraction & -0.06 & 0.21 \\
\hline Sand & -0.15 & -0.86 \\
\hline Clay & 0.42 & 0.83 \\
\hline $\mathrm{CCC}$ & 0.45 & 0.76 \\
\hline CIL & -0.22 & 0.38 \\
\hline $\mathrm{pH}$ & 0.85 & -0.01 \\
\hline WHC & -0.15 & 0.3 \\
\hline Equivalent Humidity & 0.29 & 0.83 \\
\hline Organic matter & 0.33 & 0.03 \\
\hline Calcium & 0.81 & 0.33 \\
\hline Sodium & -0.03 & 0.32 \\
\hline Potasium & 0.73 & 0.33 \\
\hline Phosporus & -0.22 & -0.91 \\
\hline Magensium & 0.64 & 0 \\
\hline Nitrogen & 0.46 & 0.17 \\
\hline Carbonates & 0.82 & 0.28 \\
\hline Active carbonates & 0.8 & 0.38 \\
\hline Conductivity & 0.82 & 0.2 \\
\hline CEC & 0.69 & 0.25 \\
\hline Saturation rate & 0.75 & 0.27 \\
\hline Eigenvalue & 6.28 & 4.62 \\
\hline Variance explained & 0.35 & 0.26 \\
\hline Cumulative variance explained & 0.35 & 0.62 \\
\hline
\end{tabular}

Note: Values in boldfaced type are loadings $>0.7$. WHC, water holding capacity.

rameter method (Cieszewski et al. 2000) to attain base age invariance. In this procedure, the global and specific parameters are estimated simultaneously and result in the same parameter estimates regardless of the base age selected.
Autocorrelation produced by longitudinal data was corrected by introducing an autoregressive procedure in the fitting phase. The continuous autoregressive error structure $(\mathrm{CAR}(p))$ was considered to be appropriate for unequally spaced longitudinal data (Gregoire et al. 1995; Zimmerman and Núñez-Antón 2001; Diéguez-Aranda et al. 2005) and was therefore used in this study. The general structure of $\operatorname{CAR}(p)$ is as follows (eq. 2):

$$
\text { [2] } \quad e_{i j}=\sum_{p=1}^{n} d_{p} \phi_{p}^{k} e_{i j-p}+\varepsilon_{i j}
$$

where $e_{i j}$ is the model error, which follows an autoregressive procedure; $d_{p}$ is 1 when $j>p$ and 0 if $j=p$; and $\phi_{p}^{k}$ is the $p$ continuous time autoregressive parameter where $k=t_{i j}-t_{i j-p}$ and $t_{j}>t_{j}-p \forall i$. A visual inspection of lag residuals revealed the suitability of a second order structure for correcting autocorrelation. Fitting was performed using the Model procedure (SAS Institute Inc. 2004a).

The site variables selected in the factor analysis were considered partially responsible for site productivity and consequently were inserted into eq. 1 assuming the following basic growth hypotheses: $(i)$ the additive effect of climate on $X$, replacing $\eta$ with a function of site variables; (ii) the multiplicative effect on $X$, by means of replacing $\alpha$ with a variable or a function of site variables; (iii) the inverse multiplicative effect on $X$ if $\gamma$ is expanded; and (iv) the exponential time transformation if $\delta$ is substituted for site descriptors. Model performance in terms of biological consistency was also tested; models that did not reflect a realistic growth trend after fitting were discarded.

\section{Model evaluation}

The model was evaluated using all the data except the set of observations for one growth series, and the mean prediction error was calculated for the omitted growth series. This procedure was repeated $n$ times, with $n$ being the number of growth series in the sample (123 plots). The mean prediction error was then presented in its absolute and relative values (eqs. 3-6). Root mean square error prediction and model efficiency were also calculated (eqs. 7-9). The initial conditions for the evaluation statistic calculations were the mean age and the corresponding height, calculated using the algorithm proposed by Carmean (1972) and modified by Newberry (1991).

$$
\begin{aligned}
\text { [3] } \quad \bar{e}_{i}=\frac{\sum_{j=1}^{k}\left(H_{j}-\widehat{H}_{j}\right)}{k} \\
\text { [4] } \quad \bar{e}_{\mathrm{ev}}=\frac{\sum_{i=1}^{n} \bar{e}_{i}}{n}
\end{aligned}
$$

[5] $\quad \overline{\operatorname{abse}}_{i}=\frac{\sum_{j=1}^{k}\left|H_{j}-\widehat{H}_{j}\right|}{k}$ 
Table 5. Model parameters estimates and fitting and evaluation statistics (continued on next page).

\begin{tabular}{|c|c|c|c|c|c|c|}
\hline \multirow{2}{*}{$\begin{array}{l}\text { Model } \\
\text { name }\end{array}$} & \multirow[b]{2}{*}{ Model structure } & \multicolumn{5}{|c|}{ Parameter estimates } \\
\hline & & $a_{0}$ & $a_{1}$ & $b_{0}$ & $b_{1}$ & $c$ \\
\hline CMA1 & eq. 11 & $0.0863(0.0037)$ & & $1.3136(0.03)$ & $-0.2434(0.025)$ & $7.7718(0.99)$ \\
\hline CMA2 & eq. 12 & $0.0253(0.0007)$ & & $1.3143(0.03)$ & $-0.2706(0.026)$ & $23.068(2.69)$ \\
\hline CMM1 & eq. 13 & $2606.59(810.3)$ & $15.87(1.06)$ & $1.341(0.03)$ & $0.231(0.06)$ & $0.0016(0.0002)$ \\
\hline CMM2 & eq. 14 & $707.59(246.2)$ & 15.67 (1.09) & $1.337(0.03)$ & $0.2335(0.06)$ & $0.006(0.0008)$ \\
\hline RM & Regional model & & & & & \\
\hline
\end{tabular}

Note: Values in parentheses are approximate SEs. MEF, model efficiency.

[6] $\quad \overline{\operatorname{abse}}_{\mathrm{ev}}=\frac{\sum_{i=1}^{n} \overline{\mathrm{abse}}_{i}}{n}$

[7] $\operatorname{RMSEP}_{i}=\sqrt{\frac{\sum_{j=1}^{k}\left(H_{j}-\widehat{H}_{j}\right)^{2}}{k-p}}$

$$
\operatorname{RMSEP}_{\mathrm{ev}}=\frac{\sum_{i=1}^{n} \operatorname{RMSEP}_{i}}{n}
$$

[9] $\quad \mathrm{MEF}=1-\frac{\sum_{i=1}^{s}\left(H_{i}-\widehat{H}_{i}\right)^{2}}{\sum_{i=1}^{s}\left(H_{i}-\bar{H}_{i}\right)^{2}}$

where $\bar{e}_{i}$ is the mean prediction error of the $i$ th growth series, $k$ is the number of observations within the same growth series, abse ${ }_{i}$ is the absolute prediction error of the $i$ th growth series, $\mathrm{RMSEP}_{i}$ is the root mean squared error of prediction of the $i$ th growth series, $p$ is the number of parameters, and $n$ is the total number of growth series. MEF is model efficiency and $s$ is the total number of observations. Subindex ev indicates total evaluation statistics.

Bias assessment was performed for the whole growth series and across age classes. However, splitting the data according to age classes reduces the available data in some classes, especially in older ones, leading to a possible lack of normality. In non-normality conditions, mean confidence intervals are doubtful and conclusions could be misleading. To deal with this problem and to interpret the results correctly a robust estimation of mean error was performed. The robust estimator chosen was the $\alpha$-Winsorized mean, which is calculated as

$$
\bar{E}_{\alpha}^{\mathrm{W}}=\frac{1}{n}\left(m E_{m+1}+E_{m+1}+\ldots+E_{n-m}+m E_{n-m}\right)
$$

where $\bar{E}_{\alpha}^{\mathrm{W}}$ is the $\alpha$-Winsorized mean, $\alpha$ is the percentage of observations to be "winsorized," $n$ is the number of observations (in this case, the number of mean error estimates calculated for that age class), $m$ is the greater entire number less than or equal to $n \alpha$, and $E_{1}, \ldots, E_{m+1}, \ldots, E_{n-m}, \ldots, E_{m}$ are the mean error observations that have to be sorted so that the $m$ smallest observations are replaced by the $(m+1)$ smallest observation and the $m$ largest observations are replaced by the $(m+1)$ largest observation (SAS Institute Inc. 2004b).

Model fitting and evaluation were undertaken jointly, since the assessment of the quality of fit does not assess the quality of future predictions (Myers 1990). Measures of bias and model efficiency both for the fitting data and the resampling procedure are presented and evaluated to select the best model.

In this study we evaluate whether the inclusion of environmental variables improves the dominant height estimates by comparing model performance with the results obtained by Bravo-Oviedo et al.'s (2007) regional model, who fitted Cieszewski's (2001) model with the same database as this study.

\section{Results}

\section{Factor analysis}

The first two factors using physiographic and climatic attributes accounted for $75.8 \%$ of variation. The variables affecting the first factor were length of the drought period (number of months in which the temperature curve is above the precipitation curve in the Walter and Lieth's (1960) climodiagram) and temperature regime. In the second factor, these variables were annual and partial rainfall in winter and autumn (from September to March). Consequently, drought length, mean annual temperature, and precipitation regimes prior to the growth season (total autumn and winter precipitation) are considered regional differentiation factors and are expected to explain regional differences in the dominant growth pattern.

Factor analysis with soil attributes revealed that magnesium and carbonate contents loaded most in the first inertia axe. The first and second axes differentiated stands located in SES. MMP is often defined as a species that prefers acid reaction, such as that originated by granite, gneiss, or sandstone rock. Nonetheless, the SES stands are of medium-high quality and they grow on basic soils. The inclusion of soil variables in the model would have been possible if records had been available for every plot. However, the soil data came from a subsample and its inclusion in the model was limited. As a result, the model includes parental material as 


\begin{tabular}{|c|c|c|c|c|c|c|c|c|}
\hline \multicolumn{3}{|c|}{ Fitting statistics } & \multicolumn{6}{|c|}{ Evaluation statistics } \\
\hline MSE & RMSE & $\operatorname{Adj}-R^{2}$ & MEF & abse $_{e v}$ & $e_{\mathrm{ev}}$ & $e_{\mathrm{ev}}(\%)$ & $\operatorname{abse}_{\mathrm{ev}}(\%)$ & $\mathrm{RMSEP}_{\mathrm{ev}}$ \\
\hline 0.39 & 0.63 & 98.75 & 97.3 & 0.67 & -0.23 & -2.93 & 7.68 & 0.99 \\
\hline 0.39 & 0.62 & 98.76 & 97.3 & 0.66 & -0.23 & -2.88 & 7.59 & 0.97 \\
\hline 0.37 & 0.61 & 98.81 & 97.1 & 0.67 & -0.1 & -1.68 & 7.68 & 0.88 \\
\hline \multirow[t]{2}{*}{0.37} & 0.61 & 98.81 & 97.1 & 0.67 & -0.11 & -1.71 & 7.7 & 1.01 \\
\hline & & & 96.8 & 0.71 & -0.18 & -2.53 & 8.14 & 1.07 \\
\hline
\end{tabular}

Fig. 2. Model efficiency by age class. RM, regional model; CMA1, climatic model A1; CMA2, climatic model A2; CMM1, climatic model M1; CMM2, climatic model M2.
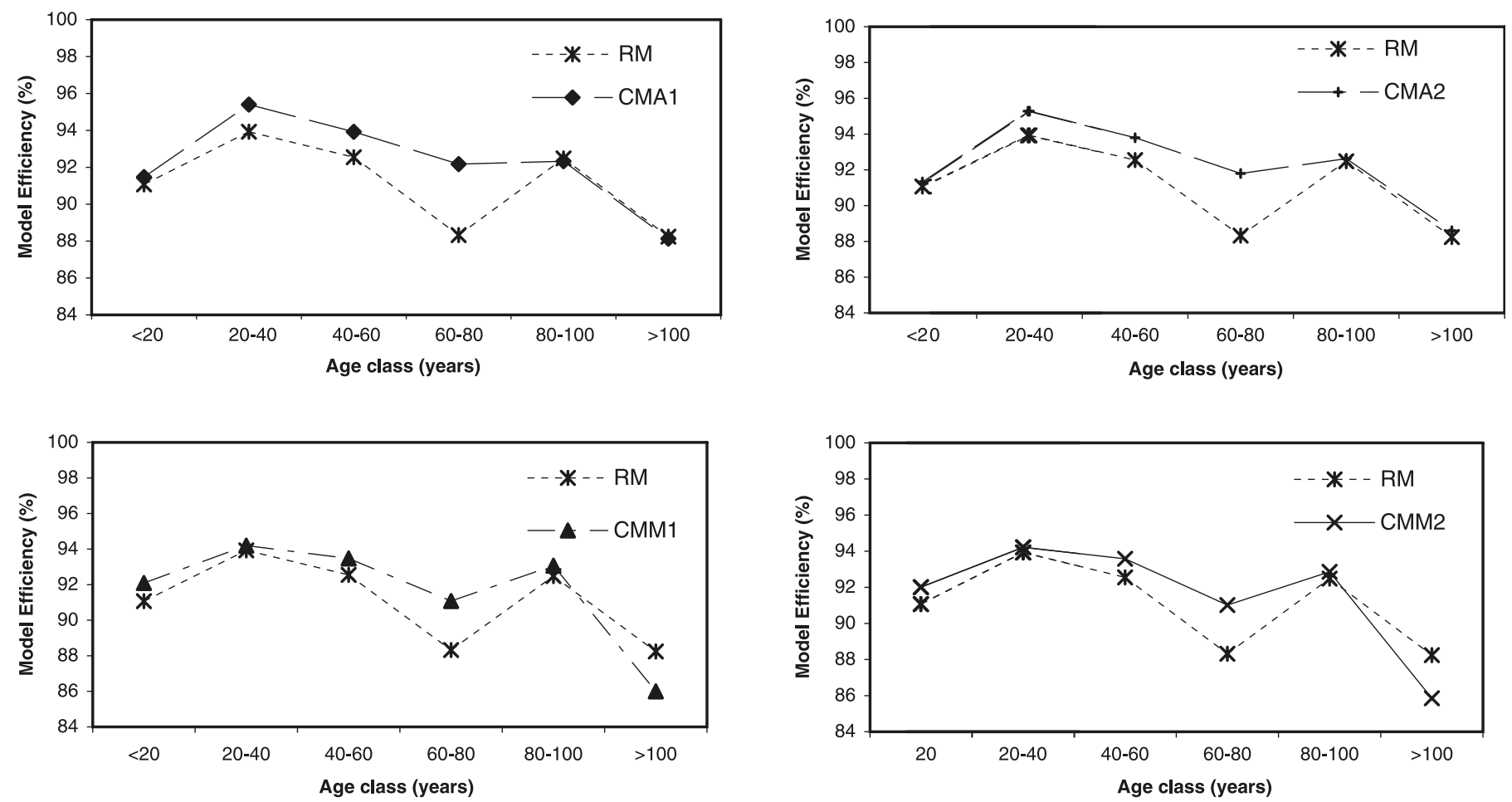

a dummy variable (DOL), which is 1 for stands located on dolomite origin soils (SES region) and 0 elsewhere. Table 4 shows the factor load pattern after varimax rotation for both climatic and edaphic data.

\section{Model fitting and evaluation}

The variables selected in factor analysis were considered responsible for regionalization. Their influence on the growth process was tested according to several assumptions. The climatic variables selected in step 1 are assumed to be related to the maximum growth potential in two possible ways: additive or multiplicative ( $\eta$ and $\alpha$ in eq. 1 , respectively), whereas climate affects half-saturation time exponentially $\left(\gamma^{\prime}=e^{\gamma}\right)$. Soil properties derived from dolomite parental material are considered to be responsible for polymorphism ( $\delta$ ) (Carmean 1972; Barnes et al. 1997).

The final models to be compared were the previous regional model (RM) and the best four climatic models. The selected climatic models shared the assumption that parameter $\delta$ is a function of parental material origin. The rest of the assumptions were $(i)$ precipitation is considered to be additive and the ratio between the root-squared temperature and drought length affects half-saturation time exponentially (eq. 11 (CMA1)), (ii) precipitation and temperature interaction is additive and drought length affects half-saturation time exponentially (eq. 12 (CMA2)), (iii) drought period length is multiplicative in the asymptote and the interaction between precipitation and the root-squared temperature affects half-saturation time exponentially (eq. 13 (CMM1)), and $(i v)$ temperature and drought period length are multiplicative in the asymptote, whereas the half-saturation time is exponentially affected by precipitation (eq. 14 (CMM2)). 
Table 6. Mean bias by age class using all data.

\begin{tabular}{lllllll}
\hline \multicolumn{7}{c}{ Age class (years) } \\
\cline { 2 - 7 } Model & $<20$ & $20-40$ & $40-60$ & $60-80$ & $80-100$ & $>100$ \\
\hline CMA1 & $-0.23^{*}$ & -0.05 & $\mathbf{- 0 . 2 3} *$ & -0.22 & -0.16 & -0.39 \\
CMA2 & $-0.24^{*}$ & -0.06 & $\mathbf{- 0 . 2 3} *$ & -0.22 & -0.16 & -0.27 \\
CMM1 & -0.04 & -0.08 & $-\mathbf{0 . 3 1} *$ & -0.21 & 0.30 & $0.52^{\dagger}$ \\
CMM2 & -0.04 & -0.08 & $-\mathbf{0 . 3 1} *$ & -0.22 & 0.29 & $0.50^{\dagger}$ \\
RM & $-0.14^{\dagger}$ & -0.07 & $-\mathbf{0 . 3 1} *$ & $-0.46^{\dagger}$ & 0.18 & 0.26 \\
\hline
\end{tabular}

Note: Values in boldfaced type are 0.2-Winsorized means. RM, regional model.

${ }^{*} p<0.001$.

${ }^{\dagger} p<0.05$.

Other models incorporating DOL for all possible parental materials were also tested but the fitting performance in all cases was inferior to those finally selected.

$$
\begin{aligned}
\eta & =a_{0} \mathrm{PR} \\
\delta & =b_{0}+b_{1} \mathrm{DOL} \\
\gamma & =c \frac{\sqrt{T}}{\mathrm{DL}+1} \\
\kappa & =2 \alpha \gamma^{\prime}, \quad \text { where } \gamma^{\prime}=e^{\gamma} \text { and } \alpha=0.5 \\
\eta & =a_{0} \mathrm{PR} \sqrt{T} \\
\delta & =b_{0}+b_{1} \mathrm{DOL} \\
\gamma & =\frac{c}{\mathrm{DL}+1} \\
\kappa & =2 \alpha \gamma^{\prime}, \quad \text { where } \gamma^{\prime}=e^{\gamma} \text { and } \alpha=0.5
\end{aligned}
$$

$$
\begin{aligned}
\gamma & =\frac{c}{\mathrm{DL}+1} \\
\kappa & =2 \alpha \gamma^{\prime}, \quad \text { where } \gamma^{\prime}=e^{\gamma} \\
\delta & =b_{0}+b_{1} \mathrm{DOL} \\
\gamma & =c \mathrm{PR} \sqrt{T} \\
\kappa & =2 \alpha \gamma^{\prime}, \quad \text { where } \gamma^{\prime}=e^{\gamma} \\
\alpha & =\frac{1}{2}\left(\frac{a_{0}}{\mathrm{DL}+1}\right) \\
\delta & =b_{0}+b_{1} \mathrm{DOL} \\
\gamma & =c \mathrm{PR} \\
\kappa & =2 \alpha \gamma^{\prime}, \quad \text { where } \gamma^{\prime}=e^{\gamma} \\
\alpha & =\frac{1}{2}\left(a_{0} \frac{\sqrt{T}}{\mathrm{DL}+1}\right)
\end{aligned}
$$

where PR is the total autumn and winter precipitation ( $\mathrm{mm})$, DL is the length of the drought period (months), and $T$ is the mean annual temperature (degrees Celsius).

Model fitting and evaluation statistics are shown in Table 5. Regional model evaluation results are included for comparison. The climatic models are similar to each other in the fitting phase, so further evaluation is needed to select the best model. A slight improvement (only $0.3 \%-0.5 \%$ ) was detected in the precision of the climatic models compared with that of the regional model. The improvement is more significant if age class is taken into consideration; for example, model CMA1 is 3.81 points more accurate for age class 60-80 than the regional model and RMSE is reduced by $17.8 \%$ with the CMM2. Figure 2 shows model evaluation efficiency across the age classes compared with the regional model.

Multiplicative models are unbiased for a stand age of $<20$ years, whereas additive models are even worse than the simple regional model, indicating that the multiplicative climate effect better explains the height growth at this stage (Table 6). Bias reduction is $>71 \%$ for this age class. For stands $>20$ years old, additive models CMA1 and CMA2 best explained the growth pattern. No bias was detected in any of the age classes except in the 40-60 year class, which was also biased in the regional model. However, the additive models reduce the mean prediction error by $8 \mathrm{~cm}$, which indicates a bias reduction of $25 \%$.

If the regions are considered separately, the model efficiency and bias study showed that the models succeeded in explaining the relationship between environmental variables and dominant forest growth. However, the results differ depending on the region considered (Fig. 3). Growth predictions for the NPS are greatly improved using climatic models.

\section{Discussion}

This study presents a dominant height growth model based on that proposed by Cieszewski (2001). The new model includes environmental attributes in the GIF definition. The empirical results suggest that climate and parental material affect the height growth pattern in MMP.

The study is motivated by the finding of large environmental variability within natural regions that were considered in a previous site index model for the same data (Bravo-Oviedo et al. 2007). Factor analysis detected differences in climate conditions within natural regions that could refute region definition; for example, the NPS is a unique seed provenance region (Alía et al. 1996), but it can be divided into two subregions (West NPS and East NPS) according to differences in precipitation and elevation. Although the biogeoclimatic conditions are homogeneous within the regions considered in the RM, small differences in temperature and precipitation affect dominant height growth and lead to biased models when age classes are considered.

The scale of the regionalization may depend, among other factors, on natural conditions, operational use, and model building strategy. A common approach for modelling regional differences is to add dummy variables representing regions. This approach requires certain homogeneity within each region in terms of climate, soil, and physiography. However, when a high level of local variability exists, for example, in climate or soil formation, as is the case in the Mediterranean basin, the regional split would lead to data insufficiency. The reason for this is that in relatively homogenous areas where resources are limited, small variations in soil nutrients or water availability can change site productivity dramatically. These variations can even occur in neighbouring sites. Therefore, global accuracy per region is greatly improved if climatic models are applied in regions where climatic or edaphic variability is high.

Tree growth trajectory is a consequence of many factors that affect tree development, such as, among others, competition, climate, and soil. A function that describes a regional growth trajectory without taking into account environmental 
Fig. 3. Model efficiency by region. For an explanation of abbreviations see Figs. 1 and 2.

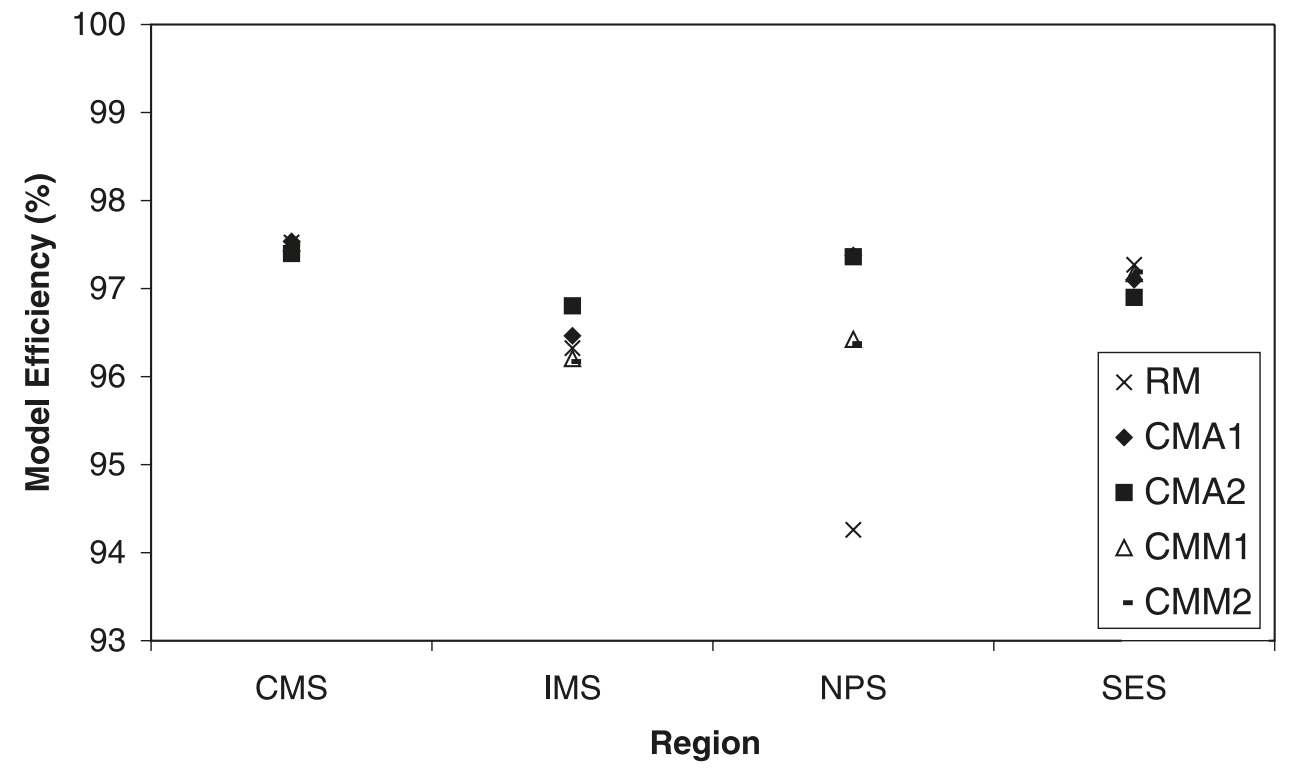

conditions is an "average" function of a number of given plots or sites. However, if the function includes climatic variables, the trajectory is unique for each plot and hence the differences in growth trajectory between one site and another depend partially on climate and soil conditions.

Our results show that the GADA formulation using climatic attributes improves dominant height growth prediction. Cieszewski and Bailey (2000) defined the GIF as the site-specific dynamics concerning growth capabilities. As climate and soil properties take part of the dynamics related to growth we have explicitly incorporated their contribution to the growth process. In this case, the GIF will explain the rest of variables related to growth dynamics that are not explicitly specified in the model.

The additive model with eq. 12 performs adequately across a wide range of climatic variation and can differentiate tree growth trajectories in dolomite conditions from those in nondolomite conditions. The effect of climate on growth trajectory varies with age class. The model structure that best describes growth in early stages, where the point of inflection is usually reached ( $<20$ years old), is multiplicative, whereas the largest differences in model efficiency between model structures occur at the 20-40 year age class. In this case, additive models perform much better than multiplicative ones. This might indicate that as long as other factors are not limited (i.e., soil depth in the early stages) the climate effect drives dominant height growth trajectory. When soil properties become scarcer and competition is greater, the effect of climate would be less patent and belowground resources would have a major effect on growth. However, this should be considered with caution until the growth process under Mediterranean conditions is satisfactory explained.

There is evidence of changing productivity over the course of the 20th century both in Iberian forests (Montero et al. 1996; Tomé et al. 1996) and in forests in other European countries, which may result in higher net annual increments (Nabuurs et al. 2002). On the other hand, rising temperatures are associated with shifts in the distribution of species and certain areas are becoming unsuitable for many species (del Barrio et al. 2006) or becoming less stable forests (Nabuurs et al. 2002). Physiological-based models require data that are not implemented in forest inventories for management purposes, although these models provide valuable information for scientific community and policy makers. Management-oriented models that include site descriptors may serve as proxies to fill the gap between forest data availability and biological-based findings. Although the absence of physiological variables in our empirical model means that it cannot be used to determine the cause-effect relationship between climate and site specific tree growth, it could nonetheless be used to assess and quantify the likely effects of climate change on the growth trajectory, as long as the model structure reflects realistically the growth theory.

\section{Conclusions}

A modification of Cieszewski's (2001) dynamic equation that includes climatic attributes has been developed. In terms of applicability, the model has proved to be more suitable to climatic regions than a previous regional model. A multiplicative effect of climate on growth potential was detected in the young phase of height growth, whereas additive effect is more plausible in older phases.

\section{Acknowledgements}

The authors wish to thank OT-02-003 project (CIFORINIA) and AGL 2004-007094-C02-02 project (Valladolid University) for their financial support. The first author would also like to thank Susana Barreiro and the staff at Departamento de Engenharia Florestal for their support and helpful comments while he was at the Istituto Superior de Agronomia in Lisbon. Many thanks to Dr. Ulises Diéguez for his comments on GADA and SAS programming. Thanks are extended to two anonymous referees for their comments on an earlier version of this work. 


\section{References}

Adame, P., Cañellas, I., Roig, S., and Río, M. 2006. Modelling dominant height growth and site index oak for rebollo oak (Quercus pyrenaica Willd.). Ann. For. Sci. 63: 929-940. doi:10. 1051/forest:2006076.

Alía, R., Martín, R., de Miguel, J., Galera, R.M., Agúndez, D., Gordo, J., Salvador, L., Catalán, G., and Gil, L.A. 1996. Regiones de Procedencia. Pinus pinaster Ait. Dirección General de Conservación de la Naturaleza, Madrid.

Alía, R., Moro, J., and Denis, J.B. 1997. Performance of Pinus pinaster provenances in Spain: interpretation of the genotype by environment interaction. Can. J. For. Res. 27: 1548-1559. doi:10.1139/cjfr-27-10-1548.

Álvarez-González, J.G., Ruíz-González, A.D., Rodríguez-Soalleiro, R., and Barrio Anta, M. 2005. Ecoregional site index models for Pinus pinaster in Galicia (northwestern Spain). Ann. For. Sci. 62: 115-127. doi:10.1051/forest:2005003.

Bailey, R.L., and Clutter, J.L. 1974. Base-Age invariant polymorphic site curves. For. Sci. 20: 155-159.

Barnes, B.V., Zak, D.R., Denton, S.R., and Spurr, S.H. 1997. Forest ecology. 4th ed. John Wiley and Sons, New York.

del Barrio, G., Harrison, P.A., Berry, P.M., Butt, N., Sanjuan, M.E., Pearson, R.G., and Dawson, T. 2006. Integrating multiple modelling approaches to predict the potential impacts of climate change on species' distributions in contrasting regions: comparison and implications for policy. Environ. Sci. Policy, 9: 129147. doi:10.1016/j.envsci.2005.11.005.

Bravo-Oviedo, A., Río, M., and Montero, G. 2007. Geographic variation and parameter assessment in generalized algebraic difference site index modelling. For. Ecol. Manage. 247: 107119. doi:10.1016/j.foreco.2007.04.034.

Calama, R., and Montero, G. 2004. Interregional nonlinear heightdiameter model with random coefficients for stone pine in Spain. Can. J. For. Res. 34: 150-163. doi:10.1139/x03-199.

Calama, R., Cañadas, N., and Montero, G. 2003. Inter-regional variability in site index models for even-aged stands of stone pine (Pinus pinea L.) in Spain. Ann. For. Sci. 60: 259-269. doi:10.1051/forest:2003017.

Carmean, W.H. 1972. Site index curves for upland oaks in the Central States. For. Sci. 2: 109-121.

Cieszewski, C.J. 2001. Three methods of deriving advanced dynamic site equations demostrated on inland Douglas-fir site curves. Can. J. For. Res. 31: 165-173. doi:10.1139/cjfr-31-1-165.

Cieszewski, C.J., and Bailey, R.L. 2000. Generalized Algebraic Difference approach: theory based derivation of dynamic site equations with polymorphism and variable asymptotes. For. Sci. 46: $116-126$.

Cieszewski, C.J., Harrison, M., and Martin, S.W. 2000. Practical methods for estimating non-biased parameters in self-referencing growth and yield models. Daniel B. Warnell School of Forest Resources, University of Georgia, Athens, Ga. PMRC-TR-2000-7.

Diéguez-Aranda, U., Burkhart, H.E., and Rodríguez-Soalleiro, R. 2005. Modeling dominant height growth of radiata pine (Pinus radiata D. Don) plantations in north-western Spain. For. Ecol. Manage. 215: 271-284. doi:10.1016/j.foreco.2005.05.015.

Dillon, W.R., and Goldstein, M. 1984. Multivariate analysis: methods and applications. John Wiley and Sons, New York.

ESRI Inc. 2006. ArcGis version 9.2. New York Street, Redlands, Calif.

Fang, Z., Bailey, R.L., and Shiver, B.D. 2001. A multivariate simultaneous prediction system for stand growth and yield with fixed and random effects. For. Sci. 47: 550-562.

González-Martínez, S.C., Slavador, L., Agúndez, D., Alía, R., and Gil, L. 2001. Geographical variation of gene diversity of Pinus pinaster Ait. in the Iberian Peninsula. In Genetic response of forest systems to changing environmental conditions. Edited by R. Schubert and G. Müller-Starck. Kluwer Academic Publishers, Dordrecht, Boston, London. pp. 161-171.

Grégoire, T.G., Schabenberger, O., and Barret, J.P. 1995. Linear modelling of irregularly spaced, unbalanced, longitudinal data from permanent-plot measurements. Can. J. For. Res. 25: 137156. doi: 10.1139/x95-017.

Hair, J.F., Anderson, R.E., Tatham, R.L., and Black, W.C. 1999. Análisis multivariante. 5th ed. Prentice Hall Iberia, Madrid.

Intergovernmental Panel on Climate Change (IPCC). 1996. Climate change. 1995. Impacts adaptations and mitigation of climate change: scientific technical analyses. Cambridge University Press, Cambridge, UK.

Lappi, J., and Bailey, R.L. 1988. A height prediction model with random stand and tree parameters: an alternative to traditional site index methods. For. Sci. 34: 907-927.

Manrique, E., and Fernández-Cancio, A. 2005. Sistema informático para la generación de datos climáticos y fitoclimáticos. In IV Congreso Forestal Español. Soc. Esp. Cien. For. Zaragoza, Spain. p. 7.

Montero, G., Rojo Alboreca, A., and Elena-Roselló, R. 1996. Case studies of growing stocks and height growth evolution in Spanish forests. In Growth trends in European forests. Edited by $\mathrm{H}$. Spiecker, K. Mielikäinen, M. Köhl, and J. Sckovsgaard. Springer, Berlin. pp. 313-328.

Montero, G., Madrigal, G., Ruiz-Peinado, R., and Bachiller, A. 2004. Red de parcelas experimentales permanentes del CIFOR-INIA. Cuad. Soc. Esp. Cien. For. 18: 229-236.

Myers, R.H. 1990. Classical and modern regression with applications. 2nd ed. Wadsworth Publishing Company, Pacific Grove, Calif.

Nabuurs, G.J., Pussinen, A., Karjalainen, T., Erhad, M., and Kramer, K. 2002. Stemwood volume increment changes in European forests due to climate change - a simulation study with the EFISCEN model. Glob. Change Biol. 8: 304-316. doi:10.1046/j. 1354-1013.2001.00470.x.

Newberry, J.D. 1991. A note on Carmean's estimate of height from stem analysis data. For. Sci. 37: 368-369.

Nicolas, A., and Gandullo, J.M. 1966. Los estudios ecológicoselvícolas y los trabajos de repoblación forestal: problemas y dificultades surgidas en la región de los páramos leoneses y palentinos. Ministerio de Agricultura. Dirección General de Montes, Caza y Pesca Fluvial. IFIE, Madrid.

Oliver, C.D., and Larson, B.C. 1996. Forest stand dynamics. John Wiley and Sons, New York.

Ribeiro, M.M., Plomion, C., Petit, R., Vendramin, G.G., and Szmidt, A.E. 2001. Variation in chloroplast single-sequence repeats in Portuguese maritime pine (Pinus pinaster Ait.). Theor. Appl. Genet. 102: 97-103. doi:10.1007/s001220051623.

Río, M., Bravo, F., Pando, V., Sanz, G., and Sierra de Grado, R. 2004. Influence of individual tree and stand attributes in stem straightness in Pinus pinaster Ait. stands. Ann. For. Sci. 61: 141-148.

Salvador, L., Alía, R., Agúndez, D., and Gil, L. 2000. Genetic variation and migration pathways of maritime pine (Pinus pinaster Ait.) in the Iberian peninsula. Theor. Appl. Genet. 100: 89-95. doi:10.1007/s001220050013.

SAS Institute Inc. 2004a. SAS/ETS(R) 9.1 User's guide, SAS Institute Inc., Cary, N.C.

SAS Institute Inc. 2004b. SAS/STAT(R) 9.1 User's guide. SAS Institute Inc., Cary, N.C.

Tomé, M., Ribeiro, F., Páscoa, F., Silva, R., Tavares, M., Palma, A., and Paulo, M.J.C. 1996. Growth trends in Portuguese for- 
ests: an exploratory analysis. In Growth trends in Europeans forests. Edited by H. Spiecker, K. Mielikäinen, M. Köhl, and J. Skovsgaard. Springer, Berlin.

Walter, H., and Lieth, H. 1960. Klimadiagramm-welt-atlas. Fisher, Vienna

Wang, G.G., Huang, S., and Morgan, D.J. 2004. Height growth pattern of lodgepole pine in relation to natural subregions in Alberta. West. J. Appl. For. 19: 154-159.
Woollons, R.C., Snowdon, P., and Mitchell, N.D. 1997. Augmenting empirical stand projection equations with edaphic and climatic variables. For. Ecol. Manage. 98: 267-275. doi:10.1016/ S0378-1127(97)00090-X.

Zimmerman, D.L., and Núñez-Antón, V. 2001. Parametric modelling of growth curve data: an overview. Test, 10: 1-73. [With discussion.] doi:10.1007/BF02595823. 
Copyright of Canadian Journal of Forest Research is the property of NRC Research Press and its content may not be copied or emailed to multiple sites or posted to a listserv without the copyright holder's express written permission. However, users may print, download, or email articles for individual use. 